Cite this as: P.V.V.N. Kishore et al. / Polyhedron 102 (2015) 361-365

Access paper at: http://dx.doi.org/10.1016/j.poly.2015.10.017

\title{
Redox shield enfolding a magnetic core
}

\author{
Pilli V.V.N. Kishore ${ }^{\text {a }}$, Amaleswari Rasamsetty ${ }^{\text {a }}$, E. Carolina Sañudo ${ }^{\text {b }}$, Viswanathan Baskar ${ }^{\text {a, }}$ \\ ${ }^{a}$ School of Chemistry, University of Hyderabad, Hyderabad 500046, India \\ ${ }^{\mathrm{b}}$ Department de Química Inorgànica i Institut de Nanociència i Nanotecnologia, Universitat de Barcelona, Diagonal 645, 08028 Barcelona, Spain
}

\section{a r t i c le info}

Article history:

Received 9 September 2015

Accepted 8 October 2015

Available online 23 October 2015

\section{Keywords:}

Multi ferrocenes

Self-assembly

Slow relaxation of magnetization

Lanthanide oxo-hydroxo clusters

Beta-diketones

\begin{abstract}
$\mathrm{a} b \mathrm{stract}$
Ferrocenyl betadiketones were reacted with hydrated lanthanide trihalides in presence of a base to yield red color solids, whose structures were characterized by single crystal X-ray diffraction technique. Structural analysis revealed the formation of nona- and tetranuclear lanthanide oxo-hydroxo clusters $\left.\left[\mathrm{Dy} 9\left(\mathbf{1}_{4}-\mathrm{O}\right)_{2}\left(\mathbf{1}_{3}-\mathrm{OH}\right)_{8}(\mathbf{1}-\mathrm{Fca})_{8}(\mathrm{Fca})_{8}\right]\right)\left[\mathrm{HN}\left(\mathrm{C}_{2} \mathrm{H}_{5}\right)_{3}\right]^{+}(1), \quad\left[\mathrm{Ln}_{4}(\mathbf{1}-\mathrm{OH})_{2}\left(\mathbf{1}-\mathrm{OCH}_{3}\right)_{4}\left(\mathrm{CH}_{3} \mathrm{OH}\right)_{2}(\mathrm{Fctfa})_{6}\right] \quad \mathrm{Ln}=\mathrm{Yb}$ (2), $\mathrm{Lu}(3)$, and $\left[\mathrm{Ln}_{4}(1-\mathrm{OH})_{2}\left(1-\mathrm{OCH}_{3}\right)_{4}\left(\mathrm{CH}_{3} \mathrm{OH}\right)_{2}(\mathrm{Fcpfa})_{6}\right] \mathrm{Ln}=\mathrm{Yb}(4), \mathrm{Lu}$ (5). Magnetism studies revealed that 1 shows slow relaxation of magnetisation. Cyclic voltammetry studies of 1 reveal electrochemically
\end{abstract} stable quasi reversible oxidation systems whereas 2-5 showed irreversible nature.

\section{Introduction}

Periphery and core functionalization of macromolecules/nano particles with redox active ferrocene [1] and synthesizing new SMMs [2] are two areas of contemporary research owing to the potential applications of these systems in the field of optics, electronics and in designing new generation magnetic data storage devices [3]. Multiferrocene architectures have been assembled primarily by using coordination driven self-assembly approach [4] or by following multi step synthetic pathways for synthesizing dendrimers decorated with ferrocenyl periphery [5]. Recently synthesis and structural characterization of a fascinating molecular cluster built on $\mathrm{Ag}_{2} \mathrm{~S}$ framework $\left[\mathrm{Ag}_{48}\left(\mathrm{l}_{4}-\mathrm{S}\right)_{6}\left(\mathrm{l}_{2 / 3}-\mathrm{SCH}_{2} \mathrm{Fc}\right)_{36}\right]$ anchoring thirty six ferrocenes have been reported [6]. In fact till date this is the largest multiferrocene architecture that has been characterized by using single crystal X-ray diffraction technique. By reacting silylated ferrocenyl chalcogenide reagents with metal acetates, it has been shown that eighteen and twelve ferrocenes can also be anchored on silver sulfide cluster surfaces [7]. Various other metal oxo clusters anchoring multiferrocene assemblies [8] are known. An interesting cubane shaped lanthanide based oxo cluster anchoring eight ferrocenes has been reported form Peter Roesky et al. [9]. In this article, results obtained in synthesizing bi-functional/multiferrocene architectures are presented. Synthesis, structure, magnetism (for 1) and cyclic voltammetry studies of $\left[\mathrm{Dy}_{9}\left(\mathrm{l}_{4}-\mathrm{O}\right)_{2}\left(\mathrm{l}_{3}-\mathrm{OH}\right)_{8}(\mathrm{l}-\mathrm{Fca})_{8}(\mathrm{Fca})_{8}\right]\left[\mathrm{HN}\left(\mathrm{C}_{2} \mathrm{H}_{5}\right)_{3}\right]$ (1) $\left[\mathrm{Ln}_{4}(\mathrm{l}-\mathrm{OH})_{2}\left(\mathrm{l}-\mathrm{OCH}_{3}\right)_{4}\left(\mathrm{CH}_{3} \mathrm{OH}\right)_{2}(\mathrm{Fctfa})_{6}\right] \mathrm{Ln}=\mathrm{Yb}(2), \mathrm{Lu}(3)$, and

\footnotetext{
$\Uparrow$ Corresponding author. Tel.: +9140 66794825; fax: +914023012460

E-mail address:vbsc@uohyd.ernet.in (V. Baskar).
}

$\left[\mathrm{Ln}_{4}(\mathrm{l}-\mathrm{OH})_{2}\left(\mathrm{l}-\mathrm{OCH}_{3}\right)_{4}\left(\mathrm{CH}_{3} \mathrm{OH}\right)_{2}(\mathrm{Fcpfa})_{6}\right] \mathrm{Ln}=\mathrm{Yb}(4), \mathrm{Lu}(5)$ are presented herein.

\section{Experimental section}

\subsection{General procedures}

The ferrocene b-diketone ligands were prepared according to the literature procedures $[10,11]$. A Thermo Finnigan Flash EA1112 series elemental analyzer was used for the microanalyses $(\mathrm{C}, \mathrm{H}, \mathrm{N})$. The infrared spectra of all the compounds were recorded in $\mathrm{KBr}$ pellets on a Jasco-5300 FT-IR spectrophotometer. Transmission electron microscope (TEM) imaging and selected area electron diffraction were carried out on a Tecnai G2FEI F12 TEM at an accelerating voltage of $200 \mathrm{kV}$. Carbon-coated copper grid loaded with crystalline powder sample has been used to record the TEM images. Mass spectra were recorded on HRMS-ESI-TOF-MAXIS BRUKER instrument. Cyclic voltammetric measurements for compounds (1-5) were performed with the help of a $\mathrm{CH}$-Instruments model 620A electrochemical analyzer using dichloromethane solutions of the complexes containing tetrabutylammonium per chlorate (TBAP) as the supporting electrolyte. A platinum disk working electrode, a platinum wire auxiliary electrode and an $\mathrm{Ag} / \mathrm{AgCl}$ reference electrode were used in the three electrode measurements at $298 \mathrm{~K}$ under dinitrogen atmosphere. NETZSCH STA 409 PC model is used for thermogravimetric analysis (TGA) to examine the thermal stability. Magnetic measurements were carried out on polycrystalline sample (circa $30 \mathrm{mg}$ ) of 1 with a Quantum Design SQUID MPMS-XL magnetometer equipped with a $5 \mathrm{~T}$ magnet. Diamagnetic corrections were calculated using 
Pascal's constants and an experimental correction for the sample holder was applied.

\subsection{General synthetic procedure}

Hydrated $\mathrm{LnCl}_{3}[\mathrm{Ln}=\mathrm{Dy}(1), \mathrm{Yb}(2,4), \mathrm{Lu}(3,5)$ and ligands (HFca, HFctfa, HFcpfa) were dissolved in $20 \mathrm{ml}$ of methanol; excess triethtylamine was added slowly stirring continued for $12 \mathrm{hrs}$ at room temperature. The precipitate formed was filtered and washed with methanol. The crystals suitable for X-ray diffraction were grown from chloroform/hexane (1) and methanol/hexane diffusion $(2-5)$. The stoichiometry and the amounts of reagents used are as follows,

1: DyCl3-6H2O $0.174 \mathrm{~g}(0.46 \mathrm{mmol})$, HFca $0.25 \mathrm{~g}(0.92 \mathrm{mmol})$, $\mathrm{Et}_{3} \mathrm{~N} 0.18 \mathrm{~g}(1.85 \mathrm{mmol})$. Yield: $0.15 \mathrm{~g}(46 \%)$. IR $\left(\mathrm{KBr} \mathrm{cm}{ }^{{ }^{1}}\right): 3424$ (b), 3090(w), 1577 (s), 1517(m), 1415(m), 1380(s), 1287(w), 1139 (s), 1029(w), 958(s), 799(m), 777(s). Decompn temp: $251{ }^{\circ} \mathrm{C}$. Elemental Anal. Cal. for $\mathrm{C}_{230} \mathrm{H}_{226} \mathrm{O}_{43} \mathrm{NFe}_{16}$ Dy9: C, 45.67; H, 3.76; $\mathrm{N}, 0.23$. Found: $\mathrm{C}, 45.81 ; \mathrm{H}, 3.71 ; \mathrm{N}, 0.28$.

2: $\mathrm{YbCl}_{5} 6 \mathrm{H}_{2} \mathrm{O} 0.119 \mathrm{~g}(0.30 \mathrm{mmol}), \mathrm{HFctfa} 0.199 \mathrm{~g}(0.61 \mathrm{mmol})$, $\mathrm{Et}_{3} \mathrm{~N} 0.12 \mathrm{~g}(1.23 \mathrm{mmol})$. Yield: $0.12 \mathrm{~g}(54 \%)$. IR $\left(\mathrm{KBr} \mathrm{cm}^{) 1}\right)$ : 3402 (b), 2920(w), 1610 (s), 1523(m), 1430(m), 1375(s), 1254(w), 1134 (s), 1024(w), 947(s), 789(m), 663(s). Decompn temp: $240{ }^{\circ} \mathrm{C}$. Elemental Anal. Cal. for $\mathrm{C}_{92} \mathrm{H}_{90} \mathrm{~F}_{18} \mathrm{Fe}_{6} \mathrm{O}_{22} \mathrm{Yb}_{4}: \mathrm{C}, 37.88 ; \mathrm{H}, 3.10$. Found: C, 37.72; H, 3.06.

3: $\mathrm{LuCl}_{3}-6 \mathrm{H}_{2} \mathrm{O} 0.120 \mathrm{~g}(0.30 \mathrm{mmol})$, HFctfa $0.199 \mathrm{~g}(0.61 \mathrm{mmol})$, $\mathrm{Et}_{3} \mathrm{~N} 0.12 \mathrm{~g}(1.23 \mathrm{mmol})$. Yield: $0.11 \mathrm{~g}(49 \%)$. IR $\left(\mathrm{KBr} \mathrm{cm}{ }^{11}\right): 3339$ (b), 2925(w), 1621(s), 1528(m), 1435(m), 1380(m), $1293(\mathrm{~s}), 1134$ (s), 942(s), 799(m), 663(s). Decompn temp: $244{ }^{\circ} \mathrm{C}$. Elemental Anal. Cal. for $\mathrm{C}_{92} \mathrm{H}_{90} \mathrm{~F}_{18} \mathrm{Fe}_{6} \mathrm{O}_{22} \mathrm{Lu}_{4}$ : C, 37.78; H, 3.10. Found: C, 37.61; H, 3.16

4: $\mathrm{YbCl}_{3}-6 \mathrm{H}_{2} \mathrm{O} 0.091 \mathrm{~g}(0.23 \mathrm{mmol})$, HFcpfa $0.175 \mathrm{~g}(0.46 \mathrm{mmol})$, $\mathrm{Et}_{3} \mathrm{~N} 0.095 \mathrm{~g}(0.94 \mathrm{mmol})$. Yield: $0.12 \mathrm{~g}(58.5 \%)$. IR $\left(\mathrm{KBr} \mathrm{cm}^{{ }^{1}}\right)$ : 3433(b), 2921(w), 1602(s), 1521(m), 1428(m), 1374(s), 1292(s), 1145(s), 1041(w), 933(s), 791(m), 666(s). Decompn temp: $249{ }^{\circ} \mathrm{C}$. Elemental Anal. Cal. for $\mathrm{C}_{98} \mathrm{H}_{90} \mathrm{~F}_{30} \mathrm{Fe}_{6} \mathrm{O}_{22} \mathrm{Yb}_{4}: \mathrm{C}, 36.58 ; \mathrm{H}, 2.81$. Found: C, 36.65; H, 2.91 .

5: $\mathrm{LuCl}_{5} 6 \mathrm{H}_{2} \mathrm{O} 0.091 \mathrm{~g}(0.23 \mathrm{mmol})$, HFcpfa $0.174 \mathrm{~g}(0.46 \mathrm{mmol})$, $\mathrm{Et}_{3} \mathrm{~N} 0.094 \mathrm{~g}(0.94 \mathrm{mmol})$. Yield: $0.13 \mathrm{~g}(69.1 \%)$. IR $\left(\mathrm{KBr} \mathrm{cm}^{\left.{ }^{1}\right)}\right)$ : 3331(b), 3089(w), 1602 (s), 1515(m), 1439(m), 1379(s), 1281(w), 1150(s), 1036(w), 1009(s), 818(m), 671(s). Decompn temp: $256{ }^{\circ} \mathrm{C}$. Elemental Anal. Cal. for $\mathrm{C}_{98} \mathrm{H}_{90} \mathrm{~F}_{30} \mathrm{Fe}_{6} \mathrm{O}_{22} \mathrm{Lu}_{4}$ : C, 36.50; $\mathrm{H}$, 2.81. Found: C, 36.62; H, 2.75 .

\subsection{X-ray crystallography}

Important crystal data parameters are given in Table 1 (S10). Selected bond lengths and bond angles for 1-5 are given in Tables 2 and 3 (S11-S12). Single crystal X-ray diffraction studies were carried out at $100 \mathrm{~K}(1$ and 5$)$ and $298 \mathrm{~K}(2,3,4)$ on a Bruker SMART $_{\text {S }}$ APEX I CCD single core area detector system equipped with a graphite monochromatic and a Mo Ka fine-focus sealed tube $(\mathrm{k}=0.71073 \AA)$ operated at $1500 \mathrm{~W}$ power $(40 \mathrm{kV}, 30 \mathrm{~mA})$. All non-hydrogen atoms with full occupancy were refined anisotropically. Hydrogen atoms were included in the structure factor calculations by using a riding model. Structure solution and refinement were performed with the help of SHELX-97 [12] programs available in the WinGX package. In 1 solvent voids were noticed but the identity of the corresponding solvent molecules of crystallization were not recognized due to poor quality of the crystal data. The solvent contributions however were removed by the SQUEEZE [13] command in the PLATON program. In 2 and 3 one of the disordered $\mathrm{CF}_{3}$ groups of ferrocene b-diketone were fixed by using PART and SADI commands and large ADP max/min ratios in structures 1-4 are removed by using EADP command. Large distance atom pairs were fixed by DFIX command. The large residual electron densities adjacent to heavy metal atoms are observed in $1-5$. The structure 1 has a Flack parameter of 0.5 , which probably suggests that it could be a racemic twin. Crystallization was tried in variety of solvents but 1 , suitable for single crystal diffraction could be crystallized only from chloroform/hexane diffusion methods. It has to be mentioned here that this Flack parameter of 0.5 does not alter the molecular structure as has been confirmed by elemental analysis, magnetic measurements studies and also the HRTEM image which shows the d spacing similar to that of the single crystal structure reported herein.

\section{Results and discussion}

Hydrated $\mathrm{DyCl}_{3}$ and $\mathrm{HFca}$ were dissolved in $20 \mathrm{ml}$ of methanol; excess triethylamine was added slowly and stirring continued for $12 \mathrm{~h}$ at room temperature (Scheme 1). The precipitate formed was filtered and washed with methanol. The crystals suitable for $\mathrm{X}$-ray diffraction of 1 were grown from chloroform/hexane diffusion method. It has to be mentioned here that the crystals of 1 were weakly diffracting, never the less satisfactory refinement of

the crystal data was possible. The solid state structure of 1 (Fig. 1) is similar to a series of $\mathrm{Ln}_{9}$ clusters reported previously [14].

The anionic metal oxo core resembles a sandglass structure. The cluster can also be described as the one containing a central Dy at the apex position sharing the two square based pyramids containing Dy atoms at the vertices. Further the metal centers are held together by oxo bridges. Each triangular face of the square pyramid is capped by a $\mathrm{l}_{3}-\mathrm{O}$ atom $\left(\mathrm{O}_{5}, \mathrm{O}_{12}\right.$ and their symmetry related counterparts) and $\{\mathrm{Dy} 4\}$ base of the square pyramidal unit are connected through two $1_{4}-\mathrm{O}$ atom $\left(\mathrm{O}_{4}, \mathrm{O}_{3}\right)$. The average Dy-O bond distances are of the order of 2.293(10)-2.566(16) A. The eight Dy atoms on the edges of $\{\mathrm{Dy} 4\}$ square bases are coordinated by 16 ferrocene $b$ diketone (Fca) ligands of which eight are chelating and eight are bridging (l-Fca). The bridging diketones connect the adjacent metal atoms at the corner of the square base. The exquisiteness of the structure lies in the fact that sixteen ferrocenes decorate the central Dy oxo/hydroxo core which is unprecedented. The approximate molecular dimension of 1 is $2.24 \times 2.01 \times .37 \mathrm{~nm}^{3}$. On analyzing HRTEM image of 1 (Fig. S1), d spacing of $14.40 \AA$ was found which correlated well with the generated powder pattern's d spacing from the single crystal diffraction data. The presence of triethylammonium cation was confirmed by ESI mass spectral measurements by a peak at $m / z=102$ which accounts for the charge neutrality.

Magnetism studies showed the $\mathrm{V} T$ value for 1 at $300 \mathrm{~K}$ is $122 \mathrm{~cm}^{3} \mathrm{~K} \mathrm{~mol}^{1}$, which is in agreement with the expected value of $127 \mathrm{~cm}^{3} \mathrm{~K} \mathrm{~mol}^{>1}$ for nine non-interacting Dy(III) ions $\left(14.16 \mathrm{~cm}^{3} \mathrm{~K} \mathrm{~mol}\right)^{1}$ per Dy(III) ions $\left({ }^{6} \mathrm{H}_{15 / 2}, S=5 / 2, L=5, J=15 / 2\right.$ and $g J=4 / 3$ ) (Fig. 2). As temperature decreases, the $\mathrm{v} T$ product decreases due to the depopulation of the Stark sub-levels of Dy (III) until it reaches a minimum at $25 \mathrm{~K}$, and then it rises again. The rise is field dependent and more accentuated with the smaller applied field of 197 Oe due to Zeeman effect, and indicates the population of a ferromagnetically coupled ground state. The magnetization versus field plot at $2 \mathrm{~K}$ clearly shows saturation at $45 \mathrm{BB}$ and can be modeled with the software PHI [15] using the giant spin model of $S=45 / 2$ and $D=\$ .030 \mathrm{~cm}^{{ }^{1}}$ (Fig. S5).

The AC magnetic susceptibility data for complex 1 at $1000 \mathrm{~Hz}$ applied frequency is shown in Fig. 2. Clearly, the tail of an out-ofphase peak can be seen, indicating the onset of a slow relaxation process taking place below $2 \mathrm{~K} . \mathrm{X}^{0} / \mathrm{X}^{00}$ AC susceptibilities with Argand plot (Fig. S8) for 1 at $1.8 \mathrm{~K}$ (red) and $4.0 \mathrm{~K}$ (white) at 1$1500 \mathrm{~Hz}$ applied frequencies are included in the supporting information which are added data for suggesting 1 does show slow 


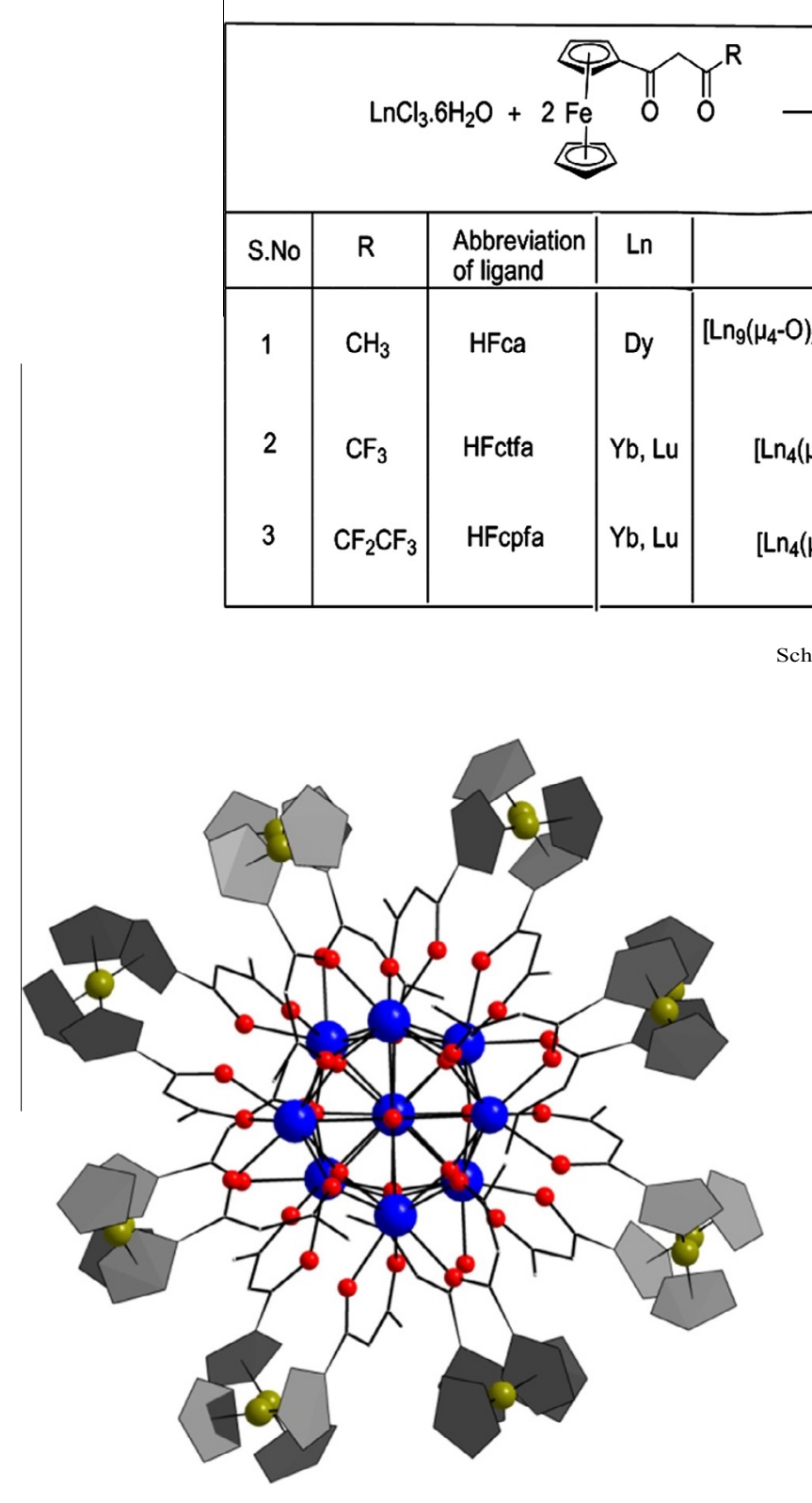

Fig. 1. Solid state structure of 1 (ball and stick representation) viewed through the $Z$ axis. Color code: blue (Dy), red $(\mathrm{O})$, green $(\mathrm{Fe})$. (Color online.)

relaxation of magnetization. Further studies investigations to confirm SMM behavior in 1 are in progress.

Cyclic voltammetric studies of 1 (Fig. S9) were carried out in oxygen free dichloromethane at room temperature with tetrabutylammonium perchlorate (TBAP) as the supporting electrolyte (Vs $\mathrm{Ag} / \mathrm{AgCl})$. Platinum was used as working electrode. Cyclic voltagrams of 1 reveals quasi reversible oxidation waves at $E_{1 / 2}$ values $1.12 \mathrm{~V}$ with $\mathrm{D} E$ values being $342 \mathrm{~m} . \mathrm{v}$, which was assigned to $\mathrm{Fc}^{+2} / \mathrm{Fe}^{+3}$ couple. The oxidation of various ferrocene units at single unique potential indicates that ferrocenes behaves similarly. Another interesting feature is the reversibility of the voltagram even after five continuous cycles which indicates that the cluster does not decompose upon oxidation.

Replacing the methyl in beta diketone used in 1 with a $\mathrm{CF}_{3}$ leads to a complete change in the self-assembly of the end product obtained on reaction with hydrated lanthanum trihalides ( $\mathrm{Yb}$, $\mathrm{Lu})$. Structural analysis of 2 reveals the formation of a tetranuclear core [16] and so are the clusters $2-5$ which also have identical
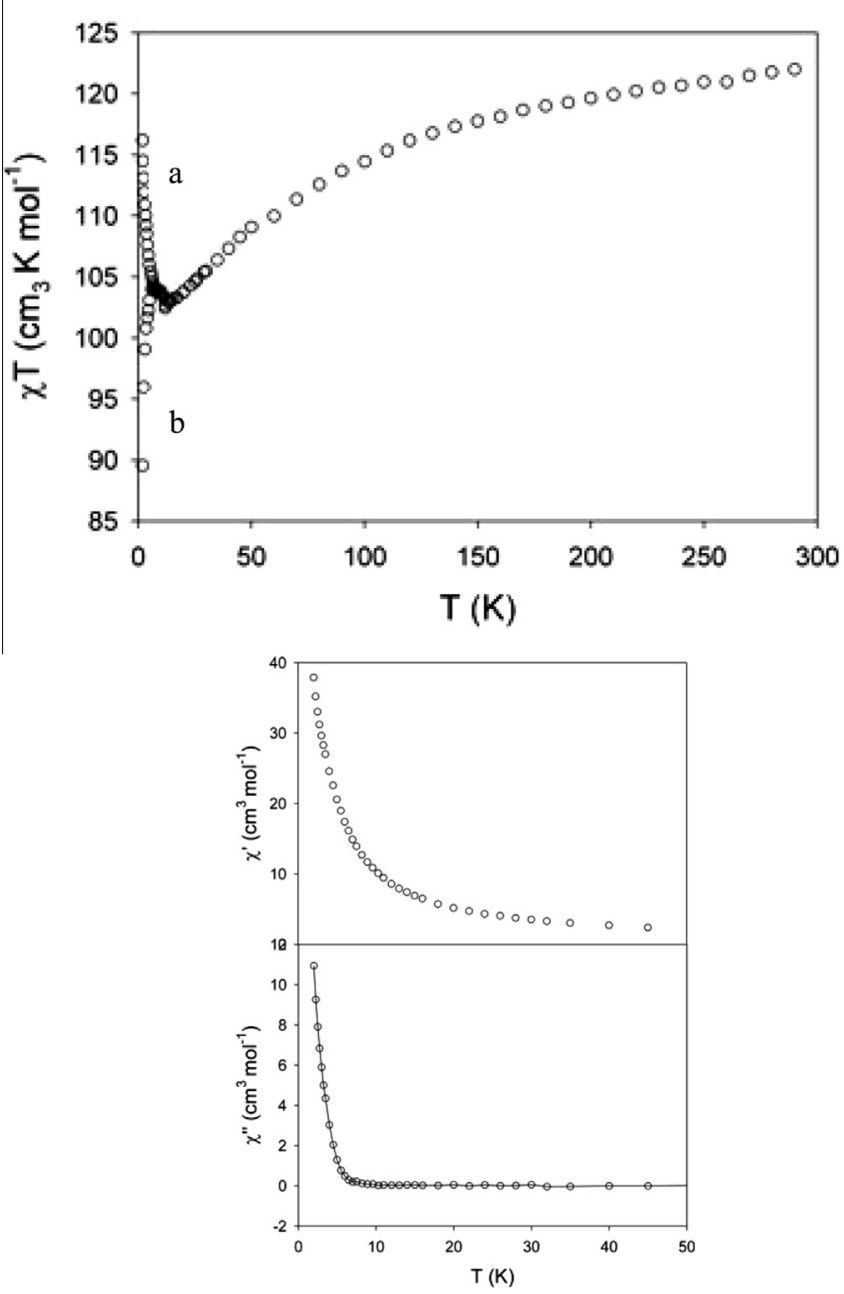

Fig. 2. vT vs $T$ plot at $197($ a) and 3000 Oe (b) applied fields and AC magnetic susceptibility plot at $1000 \mathrm{~Hz}$ for 1 .

structures in solid state. Structure of 2 is considered for discussion (Fig. 3). Compound 2 crystallizes in monoclinic $P 21 / \mathrm{c}$ space group with $Z=2$. The asymmetric crystallographic unit shows only half of the cluster, i.e. a methoxy bridged lanthanide dimer coordinated by three Fctfa ligands, two methanol molecules and a symmetry 


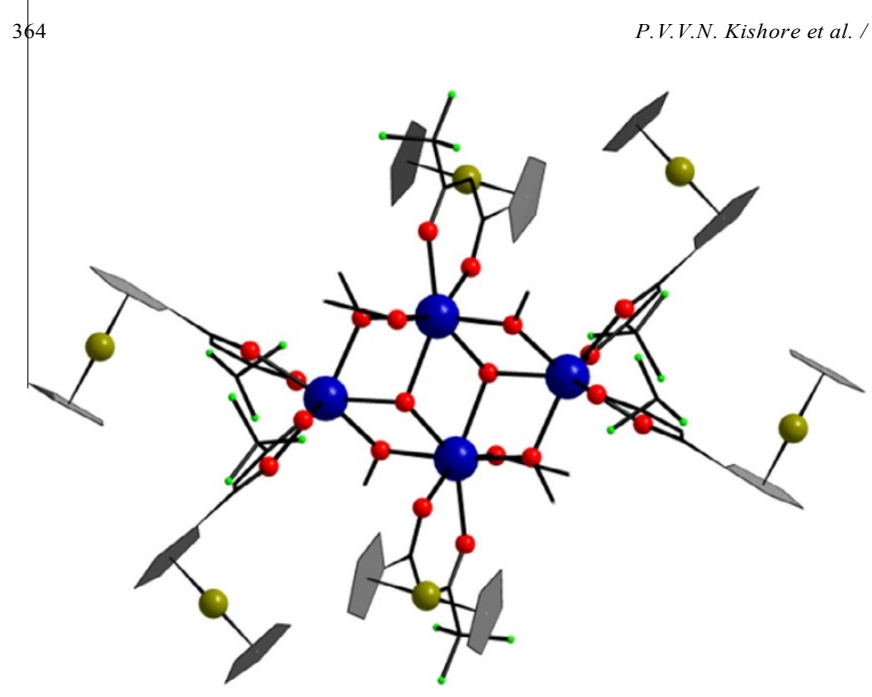

Fig. 3. Solid state structure of 2 in ball and stick representation. Color code: blue $(\mathrm{Yb})$, red $(\mathrm{O})$, green $(\mathrm{Fe})$. (Color online.)

generated oxygen atom (O10). (1-x,) y, $)$ z) symmetric operation is required to generate the cluster 2 . The cluster can be described as a butterfly structure with $\mathrm{Yb}(1)$ and $\mathrm{Yb}(1)$ located at the center and $\mathrm{Yb}(2)$ and $\mathrm{Yb}(2)$ situated at the wing tips and all the metal atoms being 7 coordinate. The metal atoms are present in a planar fashion and are bound together by two $1_{3}$-hydroxide groups and four $1_{2}$-methoxide bridges. These two $1_{3}-\mathrm{OH}$ groups are located on the opposite sides of the $\mathrm{Yb}_{4}$ plane and displaces out of the plane by $0.906 \AA$. The average $\mathrm{Yb}-\mathrm{O}$ bond distances are in the range of 2.196(3)-2.344(11) $\AA$. The peripheral part of the cluster contains six b-diketone ligands which are bound to the metal atoms in a chelating manner and hence assembling six ferrocenes on the surface of the cluster. The selected bond lengths and bond angles are shown in Table 2. The approximate molecular dimensions of compounds 2 are $1.441 \times 41.98 \mathrm{~nm}^{3}$.

Cyclic voltammetric studies shows the appearance of sharp anodic peaks at 1.16, 1.44,1.28, $1.42 \mathrm{~V}$ for compounds (2-5) respectively. On increasing the number of cycles, the peaks vanishes indicating the irreversible nature and also that 2-5 decompose up on oxidation (Fig. S10).

\section{Conclusion}

To summarize, nano-sized clusters incorporating sixteen (1) and six (2-5) have been synthesized and structurally characterized. Lanthanide oxo cores displaying interesting magnetic properties can anchor a second/third functionality and hence can act as scaffolds for assembling poly-functional molecular architectures. Investigations in this direction are in progress.

\section{Acknowledgements}

VB acknowledges Department of Science and Technology for financial Grant under the SERB programme. PVVNK thank CSIR for fellowship and AR thanks UGC for fellowship. ECS acknowledges financial support from the Spanish Government (Grant CTQ2012-32247).

\section{Appendix A. Supplementary data}

Magnetic Studies, Cyclic voltammetry, TGA plots, crystallographic data and selected bond lengths and bond angles for compounds 1-5. CCDC 973492, 984496-984499 contain the supplementary crystallographic data for this paper. These data can be obtained free of charge via http://www.ccdc.cam.ac.uk/conts/ retrieving.html, or from the Cambridge Crystallographic Data Centre, 12 Union Road, Cambridge CB2 1EZ, UK; fax: (+44) 1223-336033; or e-mail: deposit@ccdc.cam.ac.uk. Supplementary data associated with this article can be found, in the online version, at http://dx.doi.org/10.1016/j.poly.2015.10.017.

\section{References}

(a) C. Ornelas, J.R. Aranzaes, E. Cloutet, S. Alves, D. Astruc, Angew. Chem. Int. Ed. 46 (2007) 872;

(b) D. Astruc, L. Liang, A. Rapakousiou, J. Ruiz, Acc. Chem. Res. 45 (2012) 630; (c) R.L. Wolfe, R. Balasubramanian, J.B. Tracy, R.W. Murray, Langmuir 23 (2007) 2247;

(d) J.D. Qiu, M. Xiong, R.P. Liang, H.P. Peng, F. Liu, Biosens. Bioelectron. 24 (2009) 2649;

(e) M. Suziki, R. Naksjima, M. Tsurata, M. Higuchi, Y. Einaga, K. Yamamoto, Macromolecules 39 (2006) 64;

(f) M. Zamora, S. Bruna, B. Alonso, I. Cuadrado, Macromolecules 44 (2011) 7994.

[2] (a) R. Sessoli, H.L. Tsai, A.R. Schake, S. Wang, J.B. Vincent, K. Folting, D. Gatteschi, G. Christou, D.N. Hendrickson, J. Am. Chem. Soc. 115 (1993) 1804; (b) R. Sessoli, D. Gatteschi, A. Caneschi, M.A. Novak, Nature 365 (1993) 141; (c) R.J. Blagg, L. Ungur, F. Tuna, J. Speak, P. Comar, D. Collison, W. Wernsdorfer, E.J.L. McInnes, L.F. Chibotaru, R.E.P. Winpenny, Nat. Chem. 5 (2013) 673; (d) R.J. Blagg, C.A. Muryn, E.J.L. McInnes, F. Tuna, R.E.P. Winpenny, Angew. Chem. Int. Ed. 50 (2011) 6530;

(e) A.M. Ako, V. Mereacre, R. Clerac, W. Wernsdorfer, I.J. Hewitt, C.E. Anson, A. K. Powell, Chem. Commun. (2009) 544;

(f) K.C. Mondal, A. Sundt, Y. Lan, G.E. Kostakis, O. Waldmann, L. Ungur, L.F. Chibotaru, C.E. Anson, A.K. Powell, Angew. Chem. Int. Ed. 51 (2012) 7550; (g) R. Inglis, C.J. Milios, L.F. Jones, S. Piligkos, E.K. Brechin, Chem. Commun. 48 (2012) 181;

(h) C.J. Milios, A. Vinslava, W. Wernsdorfer, S. Moggach, S. Parsons, S.P. Perlepes, G. Christou, E.K. Brechin, J. Am. Chem. Soc. 129 (2007) 2754; (i) C.Z. Zaleski, E.C. Depperman, J.W. Kampf, M.L. Kirk, V.L. Pecoraro, Angew. Chem. Int. Ed. 43 (2004) 3912;

(j) C.M. Zaleski, E.C. Depperman, C. Dendrinou-Samara, M. Alexiou, J.W. Kampf, D.P. Kessissoglou, M.L. Kirk, V.L. Pecoraro, J. Am. Chem. Soc. 127 (2005) 12862;

(k) C.J. Zaleski, E. Depperman, J.W. Kampf, M.L. Kirk, V.L. Pecoraro, Inorg. Chem. 45 (2006) 10022;

(1) E.J. Schelter, F. Karadas, C. Avendano, A.V. Prosvirin, W. Wernsdorfer, K.R. Dunbar, J. Am. Chem. Soc. 129 (2007) 8139;

(m) B.S. Tsukerblat, V.A. Palii, S.M. Ostrovsky, S.V. Kunitsky, S.I. Klokishner, K. R. Dunbar, J. Chem. Theory Comput. 1 (2005) 668;

(n) S. Das, K.S. Bejoymohandas, A. Dey, S. Biswas, M.L.P. Reddy, Roser Morales, E. Ruiz, S. Titos-Padilla, E. Colacio, V. Chandrasekhar, Chem. Eur. J. 21 (2015) 6449;

(o) P. Bag, C.K. Rastogi, S. Biswas, S. Sivakumar, V. Mereacre, V. Chandrasekhar, Dalton Trans. 44 (2015) 4328;

(p) J. Goura, J.P.S. Walsh, F. Tuna, V. Chandrasekhar, Dalton Trans. 44 (2015) 1142 ;

(q) J. Goura, J. Brambleby, P. Goddard, V. Chandrasekhar, Chem. Eur. J. 21 (2015) 4926;

(r) S. Das, S. Hossain, A. Dey, S. Biswas, J.P. Sutter, V. Chandrasekhar, Inorg. Chem. 53 (2014) 5020;

(s) M. Yadav, V. Mereacre, S. Lebedkin, M.M. Kappes, A.K. Powell, P.W. Roesky, Inorg. Chem. 54 (2015) 773;

(t) D.T. Thielemann, A.T. Wagner, Y. Lan, P. Oña-Burgos, I. Fernández, E.S. Rösch, D.K. Kölmel, A.K. Powell, S. Bräse, P.W. Roesky, Chem. Eur. J. 21 (2015) 2813.

[3] (a) J. Wu, Y. Song, E. Zhang, H. Hou, Y. Fan, Y. Zhu, Chem. Eur. J. 12 (2006) 5823 ;

(b) A. Labande, J. Ruiz, D. Astruc, J. Am. Chem. Soc. 124 (2002) 1782;

(c) A. Togni, T. Hayashi, Ferrocenes: Homogeneous Catalysis, Organic Synthesis, Materials Science, VHC, Weinheim, 1994;

(d) M. Yamaouchi, D. Chiba, F. Matsukura, H. Ohno, Nature 428 (2004) 539; (e) L. Bogani, W. Wernsdorfer, Nat. Mater. 7 (2008) 179;

(f) A. Masello, K.A. Abboud, W. Wernsdorfer, G. Christou, Inorg. Chem. 52 (2013) 10414

[4] (a) K. Ghosh, J. Hu, H.S. White, P.J. Stang, J. Am. Chem. Soc. 131 (2009) 6695; (b) H.B. Yang, K. Ghosh, Y. Zhao, B.H. Northrop, M.M. Lyndon, D.C. Muddiman, H.S. White, P.J. Stang, J. Am. Chem. Soc. 130 (2008) 839.

[5] (a) A. Rapakousiou, Y. Wang, F. Nzulu, R. Djeda, N. Pinaud, J. Ruiz, D. Astruc, Organometallics 32 (2013) 6079;

(b) P. Jutzi, C. Batz, B. Neumann, H.G. Stammler, Angew. Chem. Int. Ed. 108 (1996) 2272.

[6] Y. Liu, B.K. Najafabadi, M. Azizpoor Fard, J.F. Corrigan, Angew. Chem. Int. Ed. 127 (2015) 4914.

[7] (a) D.G. MacDonald, A. Eichhofer, C.F. Campana, J.F. Corrigan, Chem. Eur. J. 17 (2011) 5890;

Y. Liu, B.K. Najafabadi, M. Azizpoor Fard, J.F. Corrigan, Angew. Chem. Int. Ed. 127 (2015) 4914. 
[8] (a) V. Chandrasekhar, S. Nagendran, S. Bansal, M.A. KoZee, D.R. Powell, Angew. Chem. Int. Ed. 39 (2000) 1833;

(b) V. Chandrasekhar, A. Chakraborty, E. Carolina Sañudo, Dalton Trans. 42 (2013) 13436;

(c) V. Chandrasekhar, K. Gopal, S. Nagendran, P. Singh, A. Steiner, S. Zacchini, J. F. Bickley, Chem. Eur. J. 11 (2005) 5437;

(d) V. Mereacre, M. Nakano, J. Gomez-Segura, I. Imaz, C. Sporer, K. Wurst, J. Veciana, C. Turta, D. Ruiz-Molina, P. Jaitner, Inorg. Chem. 45 (2006) 10443;

(e) Y. Liu, H. Hou, Q. Chen, Y. Fan, Cryst. Growth Des. 8 (2008) 1435;

(f) G. Dong, L. Yu-ting, D. Chun-ying, M. Hong, M. Qing-jin, Inorg. Chem. 42 (2003) 2519.

[9] V. Baskar, P.W. Roesky, Dalton Trans. (2006) 676.

[10] M. Fuentealba, J.R. Hamon, D. Carrillo, C. Manzur, New j. chem. 31 (2007) 1815.

[11] Q. Zhang, W.-L. Song, A.M.S. Hossain, Z.-D. Liu, G.-J. Hu, Y.-P. Tian, J.-Y. Wu, B.K. Jin, H.-P. Zhou, J.-X. Yang, S.-Y. Zhang, Dalton Trans. 40 (2011) 3510.
[12] (a) G.M. Shedrick, sheLxs-97; Program for Crystal Structure Solution, University of Göttingen, Germany, 1997;

(b) G. M. SheLXS-97; Program for Crystal Structure Solution Refinement, University of Göttingen, Germany, 1997.

[13] P.V.D. Sluis, A.L. Spek, Acta Crystallogr. A 46 (1990) 194

[14] (a) D.I. Alexandropoulos, S. Mukherjee, C. Papatriantafyllopoulou, C.P. Raptopoulou, V. Psycharis, V. Bekiari, G. Christou, T.C. Stamatatos, Inorg. Chem. 50 (2011) 11276;

(b) G. Xu, Z.-M. Wang, Z. He, Z. Lu, C.-S. Liao, C.-H. Yan, Inorg. Chem. 41 (2002) 6802 ;

(c) K. Manseki, S. Yanagida, Chem. Commun. (2007) 1242.

[15] N.F. Chilton, R.P. Anderson, L.D. Turner, A. Soncini, K.S. Murray, J. Comput. Chem. 34 (2013) 1164

[16] (a) V. Baskar, P.W. Roesky, Z. Anorg, Allg. Chem. 631 (2005) 2782; (b) S. Datta, V. Baskar, H. Li, P.W. Roesky, Eur. J. Inorg. Chem. (2007) 4216. 